\title{
Expression and mutations of $B R C A$ in breast cancer and ovarian cancer: Evidence from bioinformatics analyses
}

\author{
ZHU WANG，JIANWEN ZHANG，YING ZHANG，QIONG DENG and HUI LIANG \\ Department of Urology, People's Hospital of Longhua, Shenzhen, Guangdong 518109, P.R. China
}

Received November 18, 2017; Accepted March 27, 2018

DOI: $10.3892 /$ ijmm.2018.3870

\begin{abstract}
Breast cancer $1(B R C A 1)$ and breast cancer 2 (BRCA2) are the most well-known genes linked to breast cancer and ovarian cancer, which are crucial in DNA repair and transcriptional regulation. The present study aimed to elucidate the expression profiles, mutations and interaction networks of $B R C A 1$ and $B R C A 2$, which may provide insights to reveal the mechanisms of BRCA genes ultimately leading to breast or ovarian tumorigenesis. Bioinformatics analyses were performed in the present study. The mRNA levels of BRCAI and $B R C A 2$ were evaluated using FIREHOSE analysis, SAGE Genie tools and Oncomine analysis. cBioPortal analysis, and Catalogue Of Somatic Mutations In Cancer analysis were used to examine the BRCA1 and BRCA2 mutations. Kaplan-Meier Plotter analysis was performed to identify the prognostic roles of BRCA1 and BRCA2 in breast cancer and ovarian cancer. The results of the present study showed that the mRNA expression levels of $B R C A 1$ and $B R C A 2$ were elevated in breast cancer and ovarian cancer tissues, compared with their matched normal tissues. Second, several common mutations of $B R C A 1$ and $B R C A 2$ genes were identified in breast cancer and ovarian cancer. Finally, neurofibromin 1, synaptonemal complex protein 2 and tumor protein 53 were predicted to be involved in the interaction network of $B R C A 1$ and $B R C A 2$ in breast cancer and ovarian cancer. Taken together, these results provide a significant insight into certain mutations and proteins involved in the interaction network of BRCAI and $B R C A 2$, which may have common roles in breast cancer and ovarian cancer. However, the complex mechanism underlying these observations remains to be fully elucidated, and further investigations are required in the future.
\end{abstract}

Correspondence to: Dr Zhu Wang or Dr Hui Liang, Department of Urology, People's Hospital of Longhua, 38 Jianshe Road, Longhua, Shenzhen, Guangdong 518109, P.R. China

E-mail: wangzhu1223@163.com

E-mail: dr.lianghui@aliyun.com

Key words: breast cancer, ovarian cancer, expression profile, bioinformatics, mutation, BRCA

\section{Introduction}

Breast cancer is the most frequent type of cancer, which is expected to account for $30 \%$ of all new cancer diagnoses in women in the United States (1). Ovarian cancer is also a significant contributor to morbidity and mortality rates, ranking as the seventh most common type of cancer and the eighth most common cause of cancer-associated mortality among women (2). The majority of breast cancer cases are a result of gene mutations, particularly mutations in breast cancer 1 (BRCA1) and/or breast cancer 2 (BRCA2), which put individuals at high risk for developing a secondary breast cancer and ovarian cancer (3). The BRCA1 and BRCA2 genes are tumor suppressors. $B R C A l$ is a large gene, which comprises 24 exons located on chromosome 17 (17q21) and codes for a 1,863-amino acid protein with a zinc-binding Really Interesting New Gene finger motif at the amino terminus and a conserved acidic carboxyl terminal (BRCA1 C-terminal) motif $(4,5)$. The $B R C A 2$ gene is located on chromosome 13 (13q12), which codes for a 3,418-amino acid protein, and shares structural and functional similarities with the $B R C A 1$ protein. It is currently understood that the normal protein products of $B R C A 1$ and $B R C A 2$ genes are important in double-strand DNA repairs by maintaining genomic integrity through RAD51 (6), and they are also involved in pathways associated with homologous recombination (7). However, once either of these genes is mutated or altered, DNA damage may not be repaired properly, likely leading to the occurrence of cancer. In patients with $B R C A 1$ and/or BRCA2 mutations, the risk of breast cancer is significantly higher, compared with that in the general population, and the histological grade is also more aggressive (8-10). In addition, men and women carrying $B R C A 1$ and/or BRCA2 mutations have a $50 \%$ chance of passing the mutations on to their children, termed hereditary breast and ovarian cancer syndrome, which is characterized by an increased risk of breast cancer and ovarian cancer (11). Therefore, understanding the expression and mutations of $B R C A 1 / 2$ in breast cancer and ovarian cancer is urgently required in clinical practice, as is examining the mechanism of tumorigenesis.

Accumulated evidence has demonstrated that the expression levels of BRCAs are altered in several types of human cancer, and multiple mutations have been reported in breast cancer and/or ovarian cancer $(12,13)$. However, the comprehensive analysis of the expression and mutation of $B R C A$, and 
its interaction networks is required to provide valuable information for clinical practice and evaluation of its mechanism. The present study mainly investigated the expression levels, mutations and interaction networks of BRCA1 and BRCA2 in breast cancer and ovarian cancer using bioinformatics analyses, which aimed provide insights to reveal the mechanism of BRCA genes ultimately leading to breast or ovarian tumorigenesis.

\section{Materials and methods}

FIREHOSE analysis for BRCA1 and BRCA2. The expression profile of $B R C A 1$ and $B R C A 2$ across various human cancer types was examined through the Broad Institute FireBrowse portal (http://firebrowse.org/). On the homepage, 'BRCAl' or 'BRCA2' were added to the search box and 'View Expression Profile' was selected. The boxplots produced showed the expression level of the target gene, with red bars representing tumor samples and blue bars representing normal samples.

Oncomine database analysis. The mRNA levels of BRCAI and $B R C A 2$ in breast cancer and ovarian cancer tissues were compared with their matched normal tissues using The Cancer Genome Atlas (TCGA) datasets in the Oncomine database (http://www.oncomine.org). The threshold used to obtain the most significant probes of the queried gene for each microarray data included a two-fold difference in expression between cancer and normal tissues with a P-value of $<1 \times 10^{-4}$. For each gene, the mRNA expression level in three independent datasets was analyzed.

Kaplan-Meier Plotter analysis. The prognostic values of the $B R C A 1$ and $B R C A 2$ genes in breast cancer and ovarian cancer were analyzed using the Kaplan-Meier Plotter (http://kmplot.com/analysis/). Overall, the survival rates of patients with high and low levels of $B R C A 1$ or $B R C A 2$ were shown using a Kaplan-Meier survival plot.

Catalogue Of Somatic Mutations In Cancer (COSMIC) analysis for BRCA1 and BRCA2 mutations. The COSMIC database (http://cancer.sanger.ac.uk/cosmic) was used for the analysis of $B R C A 1$ and $B R C A 2$ mutations. Pie charts were generated for a distribution overview and substitutions on the coding strand in breast cancer and ovarian cancer.

cBioPortal analysis for alteration frequency and interaction network of BRCA1 and BRCA2. The alteration frequencies of $B R C A 1$ and $B R C A 2$ mRNA in breast cancer and ovarian cancer was determined by using the cBioPortal for Cancer Genomics (http://www.cbioportal.org/). All searches and analyses were performed according to the online instructions of cBioPortal $(14,15)$.

\section{Results}

BRCA1 and BRCA2 are upregulated in breast cancer and ovarian cancer. The gene expression levels of BRCAI and $B R C A 2$ were surveyed in 38 cases of human cancer using the TCGA database. The columns in Fig. 1 represent the accurate quantification of gene and isoform expression from the RNA-Seq data. The results showed that higher levels of $B R C A 1$ (Fig. 1A) and BRCA2 (Fig. 1B) transcripts were observed in almost all cancer tissues, compared with the levels in their matched normal tissues. Of note, the BRCAI and $B R C A 2$ genes exhibited a similar expression pattern in various cancer types, including breast cancer and ovarian cancer (Fig. 1).

Oncomine analysis comparing cancer tissues with normal tissues also showed that the BRCAl and BRCA2 genes were significantly upregulated in breast cancer and ovarian cancer tissues (Fig. 2A-D) in three independent analyses, compared with corresponding normal tissues $(16,17)$. The results of the Kaplan-Meier analysis revealed that a high expression level of $B R C A 1$ was correlated with a poor survival rate in breast cancer $(\mathrm{P}=1.51 \mathrm{E}-11$; Fig. $3 \mathrm{~A})$ and a high expression level of $B R C A 2$ was correlated with poor survival rates in breast cancer ( $\mathrm{P}=0.00093$; Fig. 3B). No significant correlation was found between the expression level of $B R C A l$ and the survival rate of patients for ovarian cancer $(\mathrm{P}=0.13$; (Fig. 3C), whereas a high expression level of $B R C A 2$ was correlated with poor survival rates in ovarian cancer $(\mathrm{P}=1.0 \mathrm{E}-9$; Fig. $3 \mathrm{D})$.

BRCA1 and BRCA2 mutations in breast cancer and ovarian cancer. The present study evaluated the mutations of BRCAI/2 using the COSMIC database, and the information regarding the mutations of substitution missense, nonsense, synonymous and insertion frame shift are presented in the pie-chart shown in Fig. 4A-D. In breast cancer and ovarian cancer, the most frequent mutation was substitution missense in the $B R C A 1 / 2$ genes. In the mutation samples of breast cancer, $50 \%$ of the BRCA1 and $54.9 \%$ of the BRCA2 mutations were substitution missense (Fig. 4A and C). In ovarian cancer, $31.87 \%$ of the $B R C A 1$ and $44.62 \%$ of the BRCA2 mutations were substitution missense (Fig. 4B and D). The mutation samples of breast cancer comprised $23.33 \% \mathrm{G}>\mathrm{A}, 20.00 \% \mathrm{G}>\mathrm{C}$ and $20.00 \%$ $\mathrm{G}>\mathrm{T}$ substitutions in the BRCAl coding strand (Fig. 4A), and $22.58 \% \mathrm{G}>\mathrm{C}$ and $19.35 \% \mathrm{G}>\mathrm{A}$ substitutions in the $B R C A 2$ coding strand (Fig. 4C). In the ovarian cancer mutation samples, there were $32.61 \% \mathrm{G}>\mathrm{T}$ and $21.71 \% \mathrm{G}>\mathrm{A}$ substitutions in the BRCA1 coding strand (Fig. 4B), and $23.68 \% \mathrm{G}>\mathrm{T}$ and 21.05 $\mathrm{G}>\mathrm{A}$ substitutions in the BRCA2 coding strand (Fig. 4D).

The alteration frequencies of $B R C A 1$ and $B R C A 2$ in breast cancer and ovarian cancer were also analyzed using cBioportal. A total of eight studies on breast cancer and two studies on ovarian cancer were included in the database. The results showed that $\sim 2-8 \%$ of breast cancer and 6-22\% of ovarian cancer clinical samples contained BRCA1 and/or BRCA2 mutations (Fig. 5A and B). In the breast cancer clinical samples, there were 81 mutations observed in $B R C A 1,43$ of which were missense mutations and 38 were in-frame mutations and truncating; there were 88 mutations in BRCA2, 42 of which were missense mutations and 46 were in-frame mutations and truncating. In ovarian cancer, there were 48 mutations of the BRCAl gene, only two of which were missense mutations and 46 were in-frame mutations and truncating; there were 46 mutations in $B R C A 2$, five of which were missense mutations and 41 were in-frame mutations and truncating. Several common mutations were observed in BRCA1 (E1346Kfs*20, E23Vfs*17 and Q1756Pfs*74) and BRCA2 (V220Ifs*4, N1784Hfs*2 and S1982Rfs*22) in breast 
A

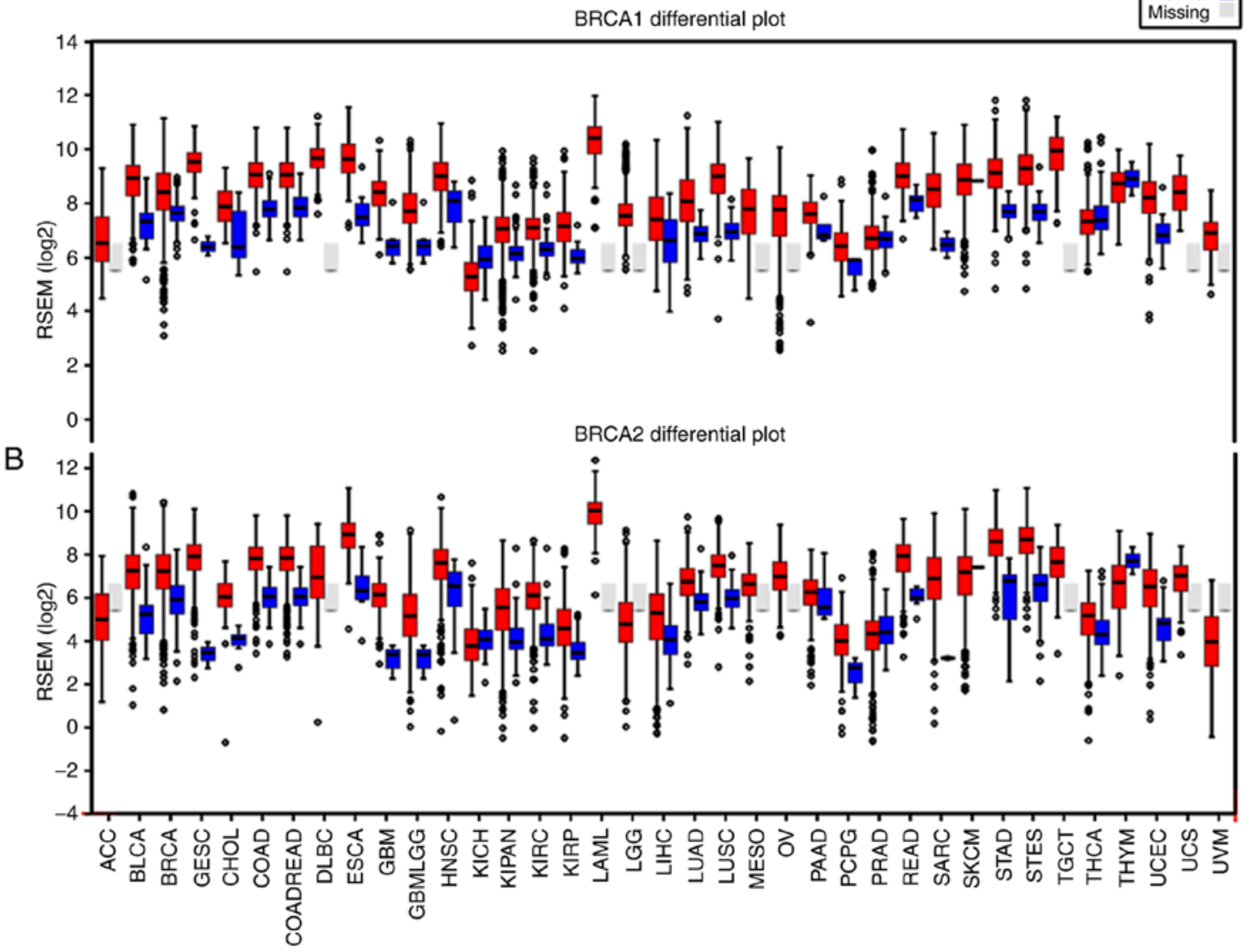

Figure 1. FIREHOSE analysis of $B R C A 1$ and $B R C A 2$ expression profiles. mRNA expression levels of (A) $B R C A 1$ and (B) $B R C A 2$ were higher in multiple types of human cancer, compared with their matched normal tissues. The boxplots show the expression levels, red bars are for tumor samples and blue bars are for normal samples. The results showed that the expression levels of BRCA1 and BRCA2 were the highest in acute myeloid leukemia (LAML) and lowest in kidney chromophobe (KICH). BRCA1, breast cancer 1; BRCA2, breast cancer 2.

Table I. Common mutations in BRCAl in breast cancer and ovarian cancer.

\begin{tabular}{lcllc}
\hline Cancer study & Amino acid change & Type & Copy number & Mutations in sample (n) \\
\hline Breast (TCGA) & E1346Kfs*20 & FS del & ShallowDel & 138 \\
Breast (TCGA) & E23Vfs*17 & FS del & Gain & 118 \\
Breast (TCGA) & Q1756Pfs*74 & FS ins & ShallowDel & 65
\end{tabular}

TCGA, The Cancer Genome Atlas; FS, frameshift; del, deletion; ins, insertion.

Table II. Common mutations in $B R C A 2$ in breast cancer and ovarian cancer.

\begin{tabular}{lcllc}
\hline Cancer study & Amino acid change & Type & Copy number & Mutations in sample (n) \\
\hline Breast (TCGA) & V220Ifs*4 & FS del & Diploid & 69 \\
Breast (TCGA) & N1784Hfs*2 & FS del & ShallowDel & 49 \\
Breast (TCGA) & S1982Rfs*22 & FS del & Diploid & 48 \\
\hline
\end{tabular}

TCGA, The Cancer Genome Atlas; FS, frameshift; del, deletion.

cancer and ovarian cancer, determined by pairwise-analysis (Tables I and II).
Interaction networks of BRCA1 and BRCA2 in breast cancer and ovarian cancer. The interaction networks of BRCAI 
A

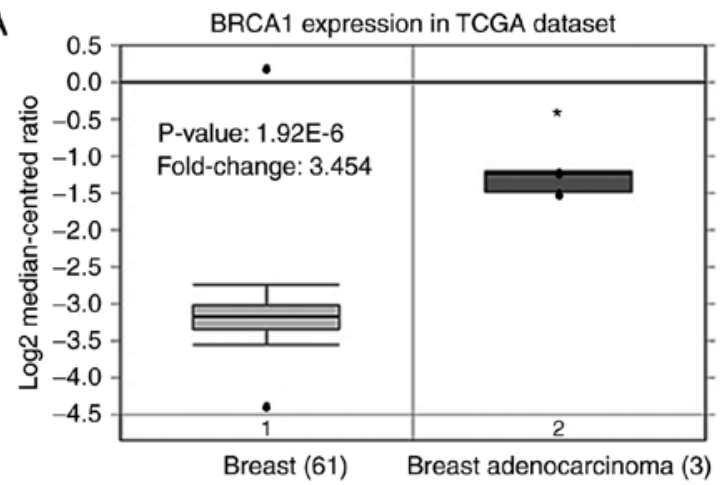

B

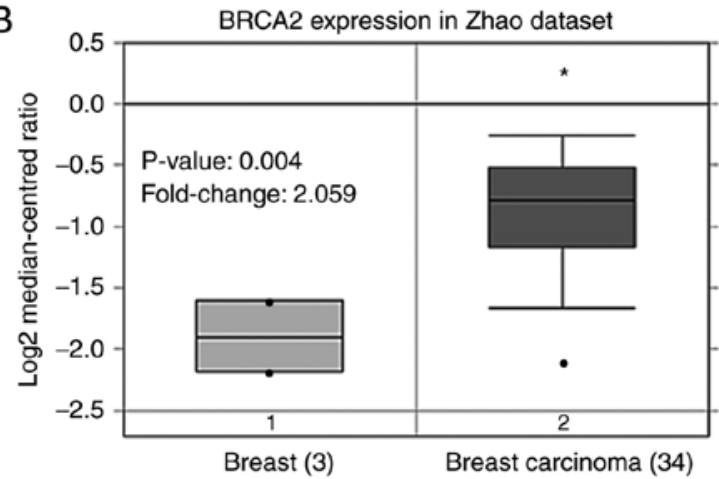

C

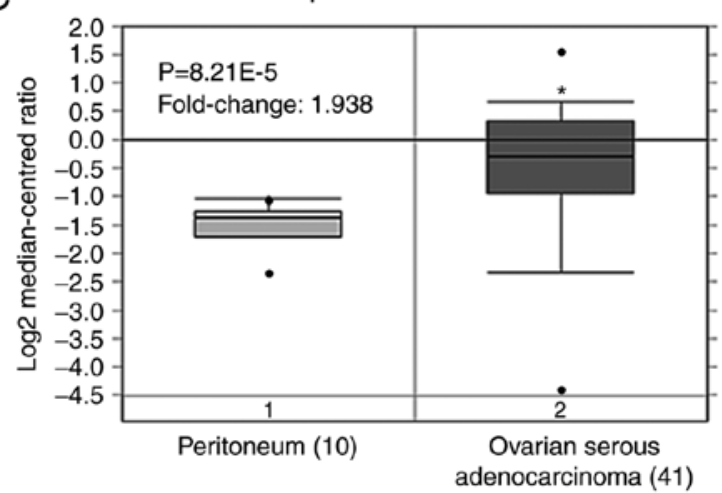

D BRCA2 expression in Bonome Ovarian dataset

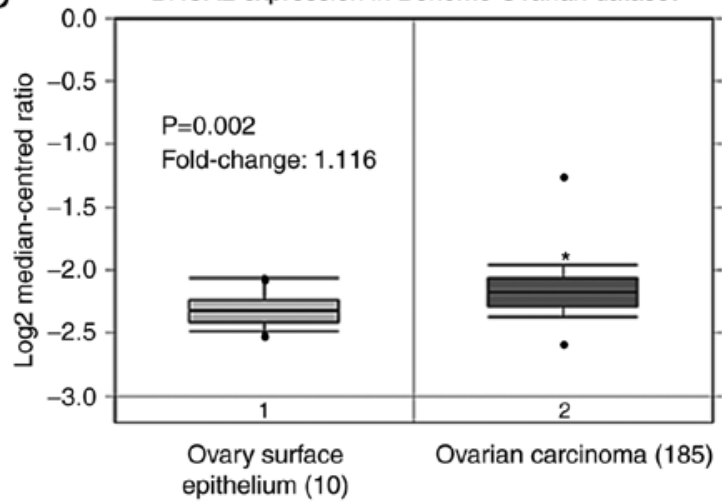

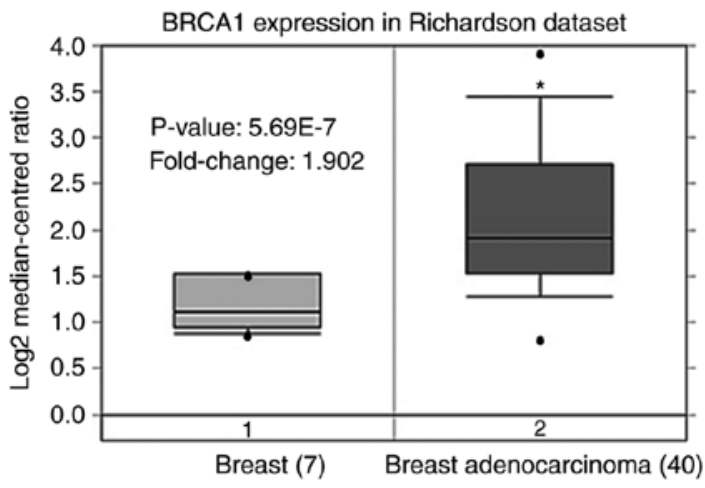
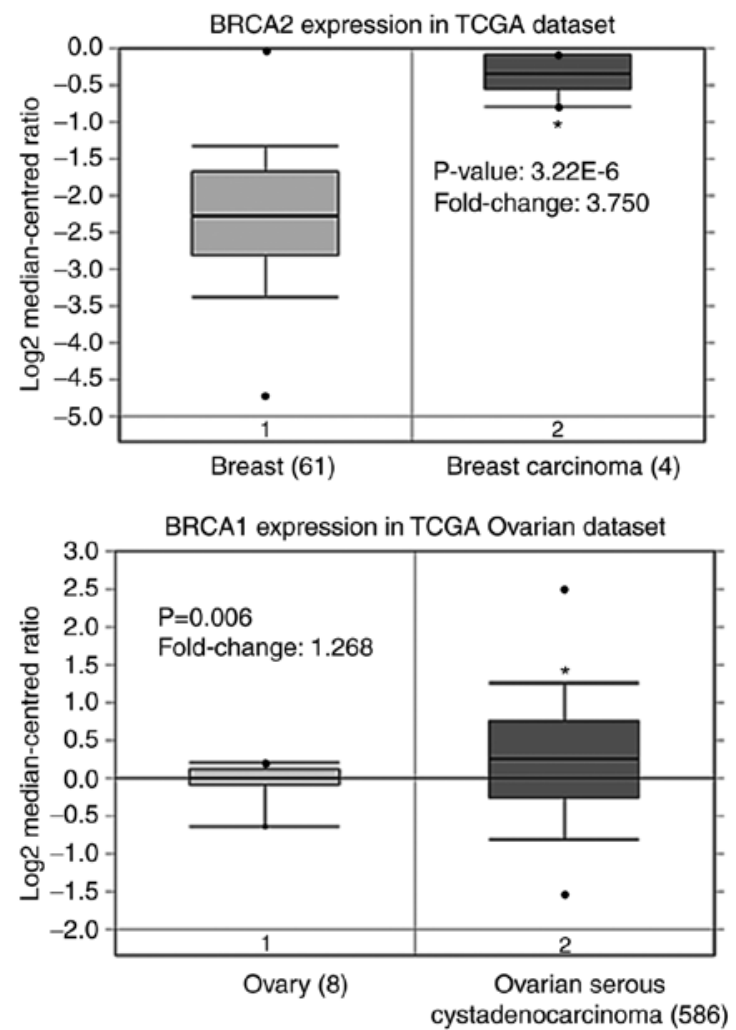

BRCA2 expression in Yoshihara Ovarian dataset

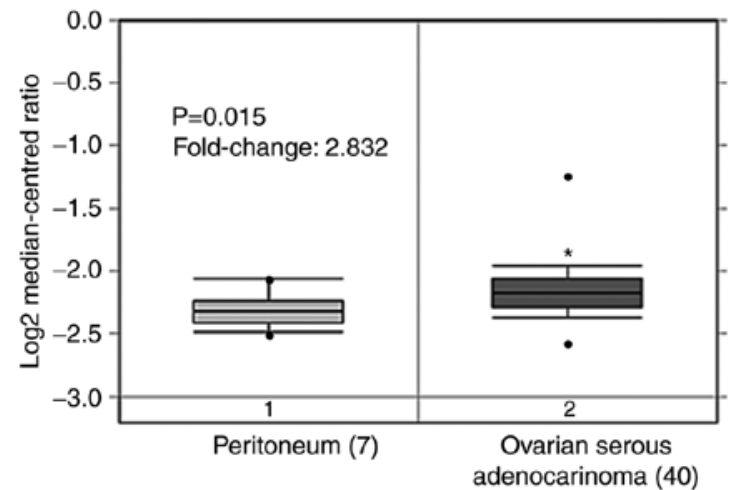

Figure 2. Evaluation of mRNA expression of BRCA1 and BRCA2 in breast cancer and ovarian cancer using Oncomine analysis. mRNA levels of (A) BRCA1 and (B) BRCA2 in breast cancer samples. mRNA levels of (C) BRCA1 and (D) BRCA2 in ovarian cancer samples. For each gene, the mRNA expression levels were analyzed in two independent datasets. ${ }^{*} \mathrm{P}<0.05$, vs. normal tissues. $B R C A 1$, breast cancer $1 ; B R C A 2$, breast cancer 2 .

and BRCA2 were analyzed using cBioportal (Fig. 5C and D). Among the genes involved in the interaction network, $>30 \%$ were able to form complexes with $B R C A 1$ and $B R C A 2$ in breast cancer $(30.6 \%)$ and ovarian cancer (36.5\%). In breast cancer,
$B R C A 1$ controlled the expression of cyclin-dependent kinase inhibitor 1B $\left(C D K N 1 B, p 27^{K i p l}\right)$. The testis expressed 15 gene controlled the state of $B R C A 1$ and $B R C A 2$, respectively. In addition, it was found that the three genes, neurofibromin 1 
A

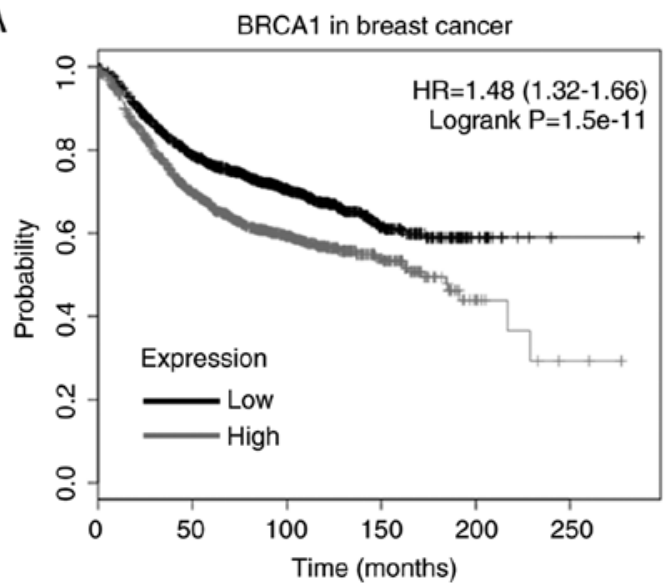

C

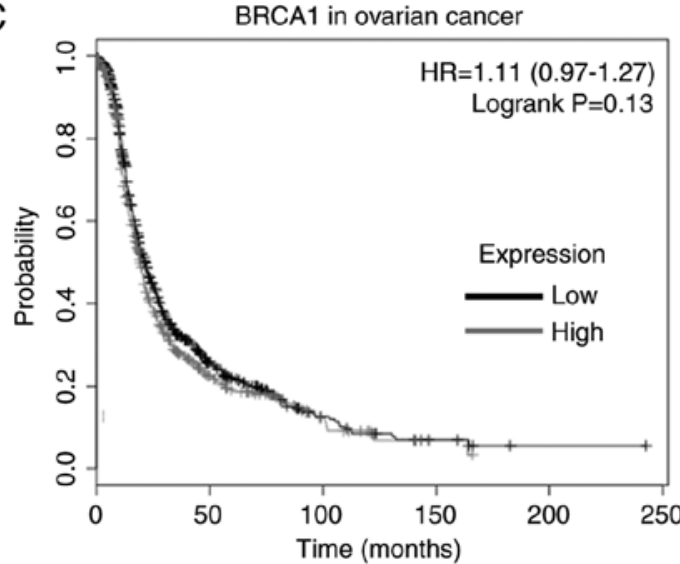

B

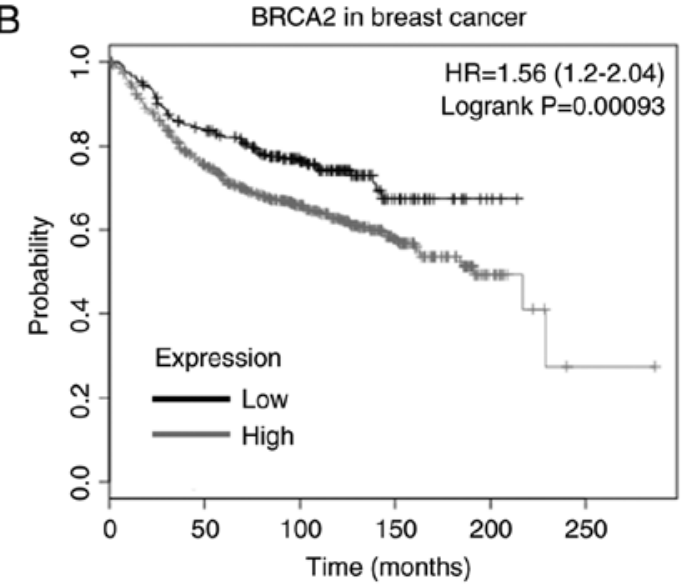

D

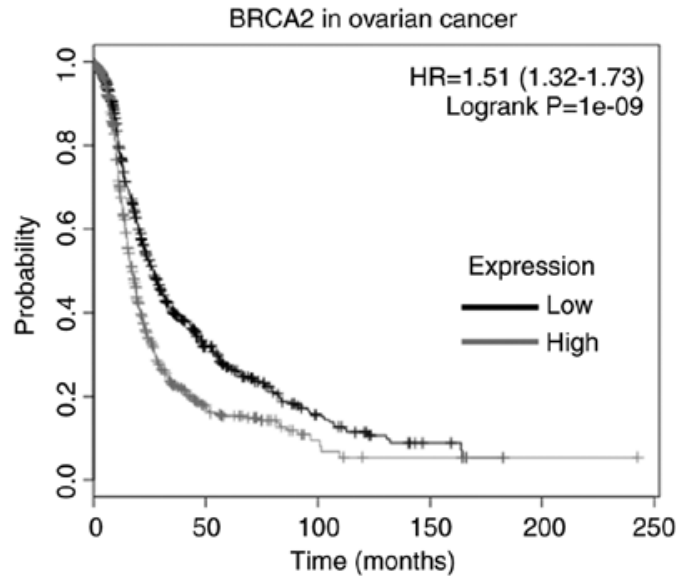

Figure 3. Kaplan-Meier Plotter analysis of BRCA1 and BRCA2 in breast cancer and ovarian cancer. Expression levels of (A) BRCA1 and (B) BRCA2 were negatively correlated with overall survival rate in breast cancer. (C) No significant correlation was observed between the expression level of BRCA1 and overall survival rate of ovarian cancer. (D) Expression level of $B R C A 2$ was negatively correlated with the overall survival rate of ovarian cancer. The red line indicates the overall survival rate with high levels of $B R C A 1$ or $B R C A 2$, and the black line indicates the low levels of $B R C A 1$ or $B R C A 2$ in breast cancer and ovarian cancer. BRCA1, breast cancer $1 ; B R C A 2$, breast cancer 2 .

(NF1), synaptonemal complex protein 2 (SYCP2) and tumor protein 53 (TP53), were involved in breast cancer and ovarian cancer. $B R C A 1$ was able to form complex with the proteins of these three genes, respectively, and also control the state change of $S Y C P 2$ in breast cancer and ovarian cancer, which is associated with cell cycle, mitotic and meiosis.

\section{Discussion}

In women, $B R C A 1$ or BRCA2 mutations result in a $\sim 40-80 \%$ risk of developing breast cancer, and $\sim 11-40 \%$ risk of developing ovarian cancer, respectively (18-21). In the present study, the latest evidence of the expression profiles and mutations of $B R C A 1$ and $B R C A 2$ were surveyed using bioinformatics analyses/TCGA data portal and revealed that the $B R C A$ genes were significantly upregulated and mutated in various types of human cancer, including breast cancer and ovarian cancer. Higher mRNA levels of BRCA1 and BRCA2 were observed in tissues samples of 23 types of cancer $\mathrm{s}$, compared with their normal control tissues, including breast cancer and ovarian cancer. This upregulated expression pattern was further validated in three independent RNA-seq datasets. Of note, a positive correlation was identified between the mRNA expression level of the BRCA genes and poor survival rates in breast cancer and ovarian cancer by Kaplan-Meier analysis.

The gene expression levels of $B R C A 1$ and $B R C A 2$ offer a potentially important tool for use in cancer management. A study in lung cancer showed that the BRCAl gene served as an indicator of chemoresistance, and the reconstitution of wild-type $B R C A 1$ function into lung cancer cells resulted in thousands of fold increases in sensitivity to paclitaxel and vinorelbine (22). Another preclinical study in breast cancer demonstrated the potential of using BRCA1 and BRCA2 dysfunction to predict response to clinical treatment (23). However, another previous study showed that the protein level of BRCAl exhibited a significant reduction in sporadic breast and ovarian cancer $(24,25)$, which may have been partially due to the different splice variants or localization of the $B R C A 1$ protein. The expression levels of $B R C A 1$ and $B R C A 2$ in human mammary epithelial and cancer cells vary with cell cycle, which are expressed in a cell cycle-dependent manner, peaking at the G1/S boundary (26).

In the present study, $\sim 81$ mutations in the $B R C A 1$ gene and 88 mutations in the $B R C A 2$ gene were found in breast cancer samples, and 48 mutations in BRCAl and 46 mutations in $B R C A 2$ were found in ovarian cancer samples. Of note, three mutations in BRCAl and three mutations in BRCA2 were 
A BRCA1 mutation distribution in breast cancer

\begin{tabular}{llll}
\hline \multirow{2}{*}{ Colour } & Mutation type & $\begin{array}{l}\text { Number of mutant } \\
\text { samples }\end{array}$ & Percentage \\
\hline & Substitution nonsense & 6 & 10.71 \\
Substitution missense & 28 & 50 \\
Substitution synonymous & 5 & 8.93 \\
Insertion in frame & 0 & 0 \\
Insertion frameshift & 5 & 8.93 \\
Deletion in frame & 1 & 1.79 \\
Deletion frameshift & 7 & 12.5 \\
Complex & 0 & 0 \\
Other & 1 & 1.79 \\
\hline
\end{tabular}

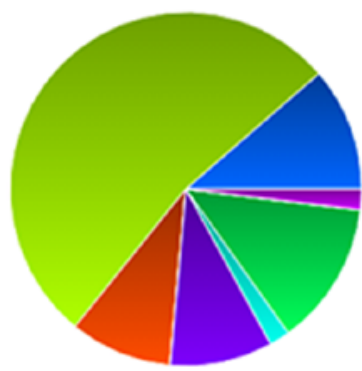

B BRCA1 mutation distribution in ovarian cancer

\begin{tabular}{llll}
\hline Colour & Mutation type & $\begin{array}{l}\text { Number of mutant } \\
\text { samples }\end{array}$ & Percentage \\
\hline & Substitution nonsense & 24 & 26.37 \\
& Substitution missense & 29 & 31.87 \\
Substitution synonymous & 1 & 1.1 \\
Insertion in frame & 0 & 0 \\
Insertion frameshift & 7 & 7.69 \\
Deletion in frame & 0 & 0 \\
Deletion frameshift & 21 & 23.08 \\
Complex & 0 & 0 \\
Other & 7 & 7.69 \\
\hline Total unique samples & 91 & \\
\hline
\end{tabular}

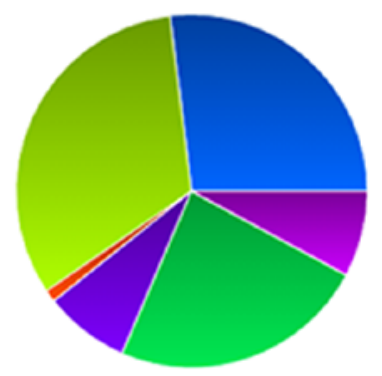

C BRCA2 mutation distribution in breast cancer

\begin{tabular}{llll}
\hline Colour & Mutation type & $\begin{array}{l}\text { Number of mutant } \\
\text { samples }\end{array}$ & Percentage \\
\hline & Substitution nonsense & 8 & 15.69 \\
Substitution missense & 28 & 54.9 \\
Substitution synonymous & 4 & 7.84 \\
Insertion in frame & 0 & 0 \\
Insertion frameshift & 2 & 3.92 \\
Deletion in frame & 1 & 1.96 \\
Deletion frameshift & 7 & 13.73 \\
Complex & 0 & 0 \\
Other & 0 & 0 \\
Total unique samples & 51 & \\
\hline
\end{tabular}

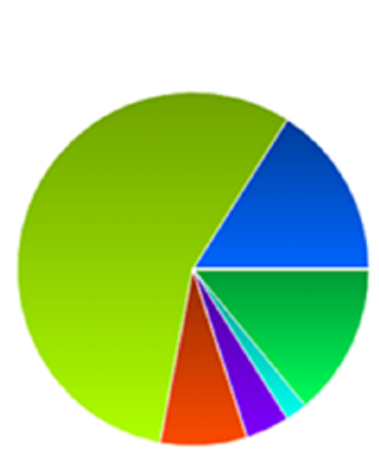

D BRCA2 mutation distribution in ovarian cancer

\begin{tabular}{llll}
\hline \multirow{2}{*}{ Colour } & Mutation type & $\begin{array}{l}\text { Number of mutant } \\
\text { samples }\end{array}$ & Percentage \\
\hline & Substitution nonsense & 12 & 18.46 \\
Substitution missense & 29 & 44.62 \\
Substitution synonymous & 0 & 0 \\
Insertion in frame & 0 & 0 \\
Insertion frameshift & 1 & 1.54 \\
Deletion in frame & 0 & 0 \\
Deletion frameshift & 19 & 29.23 \\
Complex & 0 & 0 \\
Other & 2 & 3.08 \\
\hline
\end{tabular}

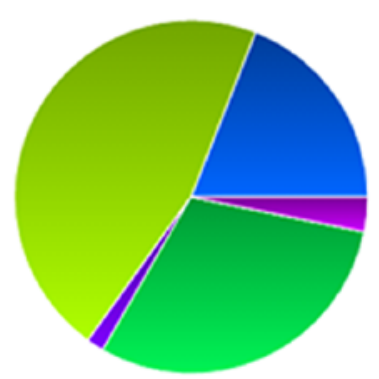

Figure 4. COSMIC analysis of $B R C A 1$ and $B R C A 2$ mutations. The pie-chart shows the percentages of the types of mutations of $B R C A 1$ and $B R C A 2$ in breast cancer and ovarian cancer according to the COSMIC database. (A) BRCA1 and (C) BRCA2 mutations in breast cancer. (B) BRCA1 and (D) BRCA2 mutations in ovarian cancer. COSMIC, Catalogue Of Somatic Mutations In Cancer; BRCA1, breast cancer 1; BRCA2, breast cancer 2.

observed in both breast cancer and ovarian cancer, which indicated that the effects of these mutations may be common in breast cancer and ovarian cancer. In addition, the common mutations in BRCA1 and BRCA2 were frame-shift deletions, and are known to be oncogenic (27).
It is well known that $B R C A 1$ and $B R C A 2$ are involved in DNA repair, cell cycle checkpoint regulation and transcription (28), and these processes are dictated through crosstalk with a network of proteins. It is now clear that the BRCA1 and BRCA2 proteins co-localize with RAD51 
A

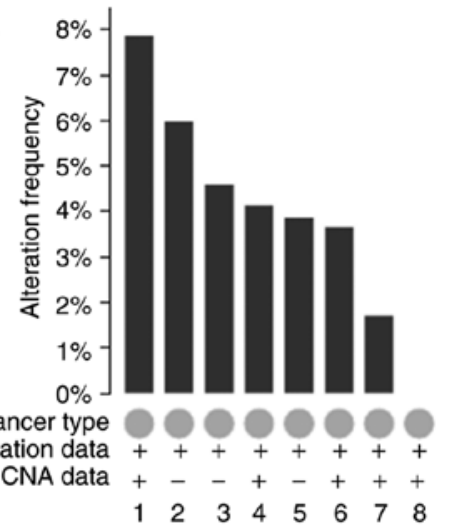

Breast cancer study

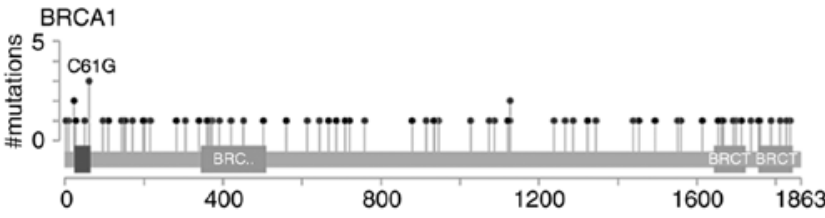

1. Breast, TCGA pub

2. Breast, BCCRC 2012

3. Breast, Sanger

4. Breast, TCGA 2015

5. Breast, Broad 2012

6. Breast, METABRIC 2012

7. ACbC, MSKCC/Breast 2015

8. Breast, BCCRC Xenograft

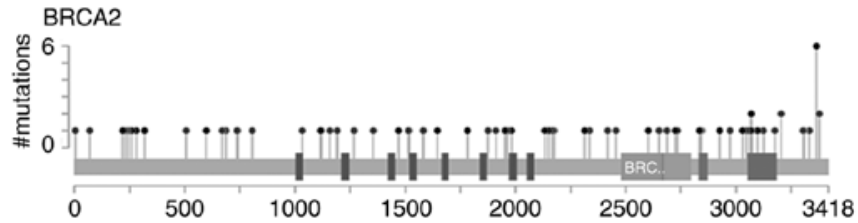

B

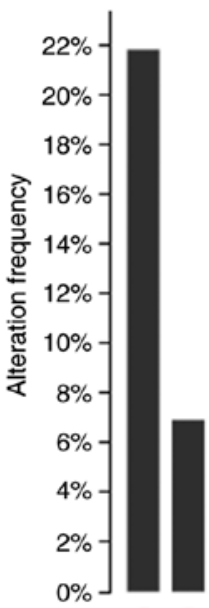

Cancer type

Mutation data +

CNA data ++

12

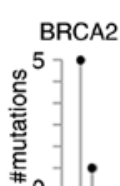

Ovarian cancer study
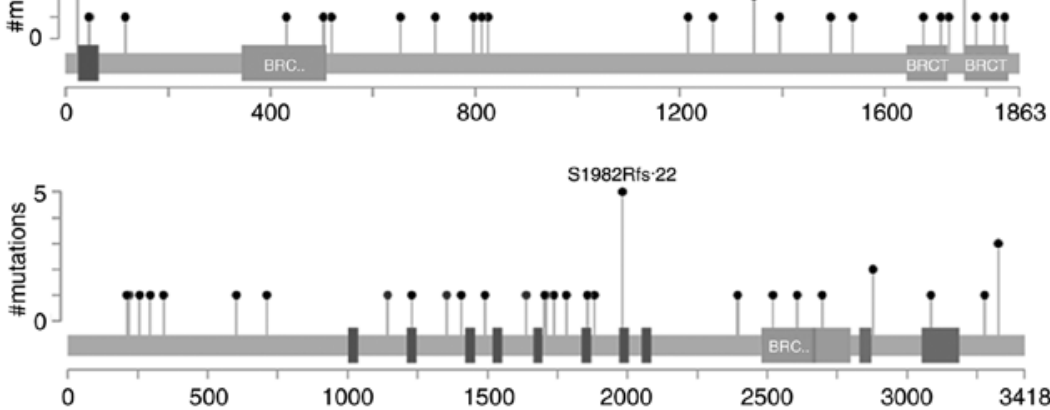

1. Ovarian, TCGA pub

2. Ovarian, TCGA

C

Breast invasive carcinoma

(TCGA, Nature 2012)

D

Ovarian serous cystadenocarcinoma

(TCGA, Nature 2011)
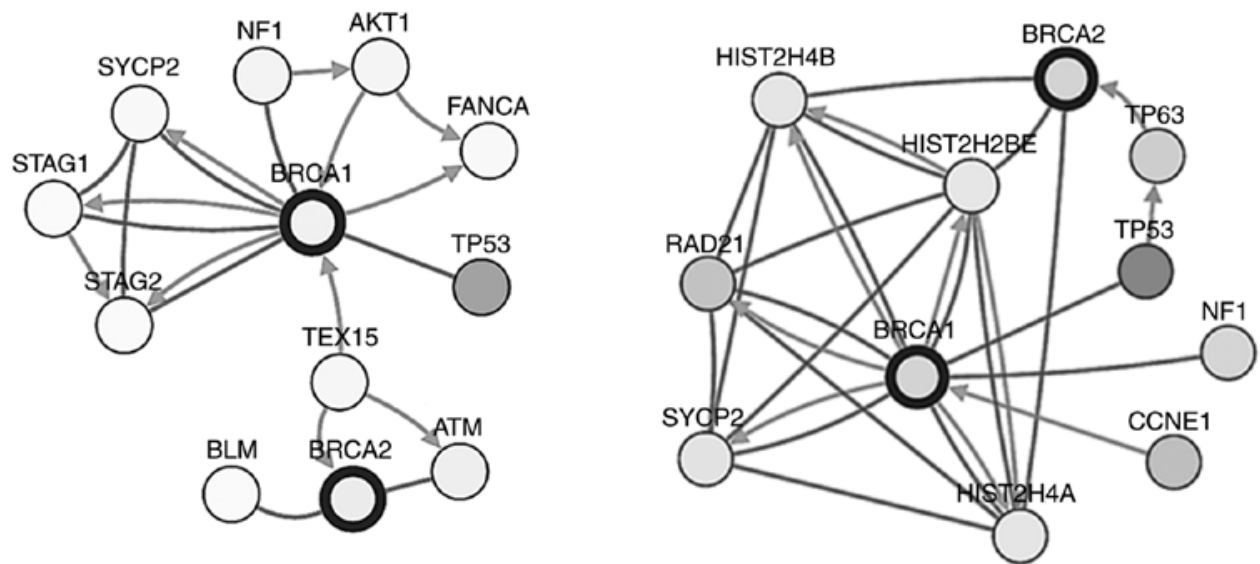

Figure 5. Alteration frequencies and interaction networks of $B R C A 1$ and $B R C A 2$ in breast cancer and ovarian cancer analyzed using cBioPortal. Mutation analysis of $B R C A 1$ and $B R C A 2$ in (A) breast cancer and (B) ovarian cancer. The results showed that $\sim 2-8 \%$ of breast cancer and $6-22 \%$ of ovarian cancer clinical samples contained the $B R C A 1$ and/or $B R C A 2$ mutation. Interaction network analysis for (C) breast cancer and (D) ovarian cancer using cBioPortal. The spheres represent the genes in the interaction networks, the green arrows mean 'control expression of', the brown lines mean 'complex with' and the blue arrows mean the 'control state change of '. TCGA, The Cancer Genome Atlas; BRCA1, breast cancer 1; BRCA2, breast cancer 2; NF1, neurofibromin 1; TP53, tumor protein 53; TEX15, testis expressed 15; ATM, ataxia telangiectasia mutated; BLM, bloom syndrome RecQ like helicase; STAG1, stromal antigen 1; SYCP2, synaptonemal complex protein 2; FANCA, fanconi anemia complementation group A; CCNE1, cyclin E1; HIST2H, histone cluster 2; TP63, tumor protein 63. 
complexes on mitotic and meiotic chromosomes following exposure to ionizing radiation or hydroxyurea $(7,29)$. Certain other proteins have been reported to interact with BRCA1, including ataxia telangiectasia mutated (ATM)/ATM-related kinase, checkpoint kinase 2, and aurora A protein kinase, to regulate cell cycle progression (30). In the present study, three genes (NF1, SYCP2 and TP53) were found to be associated with $B R C A l$ in breast cancer and ovarian cancer. $N F 1$ is a tumor suppressor gene, which comprises 60 exons coding for the protein neurofibromin, which is associated with neurofibromatosis-noonan syndrome and neurofibromatosis, type 1 . Among its associated pathways are the mitogen-activated protein kinase signaling pathway and Ras signaling pathway (31). The NFI and BRCAl genes are located in the long arm of chromosome 17, and the involvement of NFI in breast cancer has been suggested in previous publications $(32,33)$. SYCP2 is a testis-specific human gene with aberrant expression in human papillomavirus-positive cancer (34), and head and neck squamous cell carcinoma (35). In the present study, it was found that BRCAl was able to form a complex with $N F 1$ and $S Y C P 2$, respectively, in breast cancer and ovarian cancer, which suggested that the $B R C A I$ gene interacts with $N F 1$ and $S Y C P 2$ directly or indirectly in cell cycle regulation. However, further investigations are required to discern the complex mechanisms underlying these observations in the future.

In conclusion, the findings of the present study revealed not only the increased expression pattern of the $B R C A I$ and $B R C A 2$ genes in breast cancer and ovarian cancer, but also provided an understanding on the mutations and interaction networks of these two genes in the types of cancers mentioned. The results also provide significant insight into certain mutations and proteins involved in the interaction network, the roles of which may be common in breast cancer and ovarian cancer.

\section{Acknowledgements}

Not applicable.

\section{Funding}

This study was financially supported by the Shenzhen Science and Technology Program (Basic Research Project; grant no. JCYJ20170307141840188) and the Innovation and Technology fund of Longhua Shenzhen (grant no. 20150925A0410013).

\section{Availability of data and materials}

The data that support the findings of this study are available from The Cancer Genome Atlas: http://cancergenome.nih.gov/.

\section{Authors' contributions}

ZW performed the experiments and drafted the manuscript. YZ and QD performed the Oncomine analysis and cBioportal analysis. JZ and HL conceived the study design, obtained funding for the study, and drafted and revised the manuscript. All authors read and approved the final manuscript.

\section{Ethics approval and consent to participate}

Not applicable.

\section{Patient consent for publication}

Not applicable.

\section{Competing interests}

The authors declare that they have no competing interests.

\section{References}

1. Siegel RL, Miller KD and Jemal A: Cancer statistics, 2017. CA Cancer J Clin 67: 7-30, 2017.

2. Shi T, Wang P, Xie C, Yin S, Shi D, Wei C, Tang W, Jiang R, Cheng X, Wei Q, et al: BRCA1 and BRCA2 mutations in ovarian cancer patients from China: Ethnic-related mutations in $B R C A 1$ associated with an increased risk of ovarian cancer. Int $\mathbf{J}$ Cancer 140: 2051-2059, 2017.

3. Eeles RA: Screening for hereditary cancer and genetic testing, epitomized by breast cancer. Eur J Cancer 35: 1954-1962, 1999.

4. Miki Y, Swensen J, Shattuck-Eidens D, Futreal PA, Harshman K, Tavtigian S, Liu Q, Cochran C, Bennett LM, Ding W, et al: A strong candidate for the breast and ovarian cancer susceptibility gene BRCA1. Science 266: 66-71, 1994.

5. Chapman MS and Verma IM: Transcriptional activation by BRCA1. Nature 382: 678-679, 1996.

6. Kolinjivadi AM, Sannino V, de Antoni A, Técher H, Baldi G and Costanzo V: Moonlighting at replication forks - a new life for homologous recombination proteins BRCA1, BRCA2 and RAD51. FEBS Lett 591: 1083-1100, 2017.

7. Chen J, Silver DP, Walpita D, Cantor SB, Gazdar AF, Tomlinson G, Couch FJ, Weber BL, Ashley T, Livingston DM and Scully R: Stable interaction between the products of the $B R C A 1$ and $B R C A 2$ tumor suppressor genes in mitotic and meiotic cells. Mol Cell 2: 317-328, 1998.

8. Narod SA, Brunet JS, Ghadirian P, Robson M, Heimdal K, Neuhausen SL, Stoppa-Lyonnet D, Lerman C, Pasini B, de los Rios $\mathrm{P}$, et al: Tamoxifen and risk of contralateral breast cancer in BRCA1 and BRCA2 mutation carriers: A case-control study. Hereditary breast cancer clinical study group. Lancet 356 : 1876-1881, 2000.

9. Sakorafas GH and Tsiotou AG: Genetic predisposition to breast cancer: A surgical perspective. Br J Surg 87: 149-162, 2000.

10. Nicoletto MO, Donach M, De Nicolo A, Artioli G, Banna G and Monfardini S: BRCA-1 and BRCA-2 mutations as prognostic factors in clinical practice and genetic counselling. Cancer Treat Rev 27: 295-304, 2001.

11. Cicero G, De Luca R, Dorangricchia P,Lo Coco G, Guarnaccia C, Fanale D, Calò V and Russo A: Risk perception and psychological distress in genetic counselling for hereditary breast and/or ovarian cancer. J Genet Couns 26: 999-1007, 2017.

12. Alvarez C, Aravena A, Tapia T, Rozenblum E, Solís L, Corvalán A, Camus M, Alvarez M, Munroe D, Maass A and Carvallo P: Different Array CGH profiles within hereditary breast cancer tumors associated to BRCA1 expression and overall survival. Bmc Cancer 16: 219, 2016.

13. Ewald IP, Vargas FR, Moreira MA, Filho CM, da Cunha DR, Ramos JP, Ribeiro PL, Caleffi M, Giuglani R and Ashton-Prolla P: Prevalence of BRCA1 and BRCA2 founder mutations in Brazilian hereditary breast and ovarian cancer families. J Clin Oncol 26, 2008.

14. Gao J, Aksoy BA, Dogrusoz U, Dresdner G, Gross B, Sumer SO, Sun Y, Jacobsen A, Sinha R, Larsson E, et al: Integrative analysis of complex cancer genomics and clinical profiles using the cBioPortal. Sci Signal 6, 2013.

15. Cerami E, Gao J, Dogrusoz U, Gross BE, Sumer SO, Aksoy BA, Jacobsen A, Byrne CJ, Heuer ML and Larsson E, et al: The cBio cancer genomics portal: An open platform for exploring multidimensional cancer genomics data. Cancer Discov 2: 401-404, 2012. 
16. Zhao H,Langerød A, Ji Y, Nowels KW, Nesland JM, Tibshirani R, Bukholm IK, Kåresen R, Botstein D, Børresen-Dale AL and Jeffrey SS: Different gene expression patterns in invasive lobular and ductal carcinomas of the breast. Mol Biol Cell 15: 2523-2536, 2004.

17. Richardson AL, Wang ZC, De Nicolo A, Lu X, Brown M, Miron A, Liao X, Iglehart JD, Livingston DM and Ganesan S: X chromosomal abnormalities in basal-like human breast cancer. Cancer Cell 9: 121-132, 2006.

18. Mavaddat N, Peock S, Frost D, Ellis S, Platte R, Fineberg E, Evans DG, Izatt L, Eeles RA, Adlard J, et al: Cancer risks for $B R C A 1$ and $B R C A 2$ mutation carriers: Results from prospective analysis of EMBRACE. J Natl Cancer Inst 105: 812-822, 2013.

19. Chen S and Parmigiani G: Meta-analysis of BRCA1 and BRCA2 penetrance. J Clin Oncol 25: 1329-1333, 2007.

20. Blay P, Santamaria I, Pitiot AS, Luque M, Alvarado MG Lastra A, Fernández Y, Paredes A, Freije JM and Balbín M: Mutational analysis of $B R C A 1$ and $B R C A 2$ in hereditary breast and ovarian cancer families from Asturias (Northern Spain). BMC Cancer 13: 243, 2013.

21. Petrucelli N, Daly MB and Feldman GL: Hereditary breast and ovarian cancer due to mutations in $B R C A 1$ and $B R C A 2$. Genet Mod 12: 245-259, 2010

22. Taron M, Rosell R, Felip E, Mendez P, Souglakos J, Ronco MS, Queralt C, Majo J, Sanchez JM, Sanchez JJ and Maestre J: BRCAI mRNA expression levels as an indicator of chemoresistance in lung cancer. Hum Mol Genet 13: 2443-2449, 2004.

23. Farmer H, McCabe N, Lord CJ, Tutt AN, Johnson DA Richardson TB, Santarosa M, Dillon KJ, Hickson I, Knights C, et al: Targeting the DNA repair defect in $B R C A$ mutant cells as a therapeutic strategy. Nature 434: 917-921, 2005.

24. Kim MC, Choi JE, Lee SJ and Bae YK: Coexistent loss of the expressions of BRCA1 and p53 predicts poor prognosis in triple-negative breast cancer. Ann Surg Oncol 23: 3524-3530, 2016.

25. Ju LL, Zhao CY, Ye KF, Yang H and Zhang J: Expression and clinical implication of Beclin1, HMGB1, p62, survivin, BRCA1 and ERCC1 in epithelial ovarian tumor tissues. Eur Rev Med Pharmacol Sci 20: 1993-2003, 2016.
26. Rajan JV, Wang M, Marquis ST and Chodosh LA: Brca2 is coordinately regulated with Brcal during proliferation and differentiation in mammary epithelial cells. Proc Natl Acad Sci USA 93: 13078-13083, 1996.

27. Cancer Genome Atlas Network: Comprehensive molecular portraits of human breast tumours. Nature 490: 61-70, 2012

28. Welcsh PL and King MC: BRCA1 and BRCA2 and the genetics of breast and ovarian cancer. Hum Mol Genet 10: 705-713, 2001.

29. Parvin S, Islam MS, Al-Mamun MM, Islam MS, Ahmed MU, Kabir ER and Hasnat A: Association of BRCA1, BRCA2, RAD51, and HER2 gene polymorphisms with the breast cancer risk in the Bangladeshi population. Breast Cancer 24: 229-237, 2016.

30. Christou CM and Kyriacou K: BRCA1 and its network of interacting partners. Biology 2: 40-63, 2013.

31. Brems H, Beert E, de Ravel T and Legius E: Mechanisms in the pathogenesis of malignant tumours in neurofibromatosis type 1. Lancet Oncol 10: 508-515, 2009.

32. Campos B, Balmaña J, Gardenyes J, Valenzuela I, Abad O, Fàbregas P, Volpini V and Díez O: Germline mutations in NFI and $B R C A 1$ in a family with neurofibromatosis type 1 and early-onset breast cancer. Breast Cancer Res Treat 139: 597-602, 2013.

33. Madanikia SA, Bergner A, Ye X and Blakeley JO: Increased risk of breast cancer in women with NF1. Am J Med Genet A 158A: 3056-3060, 2012.

34. Masterson L, Sorgeloos F, Winder D, Lechner M, Marker A, Malhotra S, SudhoffH, Jani P, Goon P and Sterling J: Deregulation of SYCP2 predicts early stage human papillomavirus-positive oropharyngeal carcinoma: A prospective whole transcriptome analysis. Cancer Sci 106: 1568-1575, 2015.

35. Pannone G, Santoro A, Papagerakis S, Lo Muzio L, De Rosa G and Bufo P: The role of human papillomavirus in the pathogenesis of head \& neck squamous cell carcinoma: An overview. Infect Agent Cancer 6: 4, 2011. 